\title{
Russian Pattern of Altmetrics Usage based on SCI-E Statistics
}

\author{
Valentina Markusova \\ Senior Researcher \\ The All- Russian Institute for Scientific and Technical Information \\ (VINITI) of the RAS \\ Moscow 125119, Russia \\ *Senior Researcher, \\ The Institute for the Study of Science of the RAS \\ Moscow 125119 \\ Russia \\ \{valentina.markusova@gmail.com\} \\ Anna Zolotova,Natalia Kotel'nikova, Alexander Libkind \\ Researcher of the VINITI of the RAS \\ Moscow 125119 \\ Russia
}

ABSTRACT: The paper deals with the evaluation of Russian scholarly publications'impact measured by the classical indicator (citation score) and the altmetrics indicators "Usage Count Last 180 days" (U1) and "Usage Count Since 2013" (U2) during the 14 years, 2006-19. We examined research output,citation patterns and usage counts in chemistry, life sciences, mathematics and computer sciences that were indexed in the Science Citation Index - Expanded of the Web of Science (WoS).

The value of citation score and altimetric indicators (U2 and U1) were dated on July 27, 2020. We compared the mean numbers of Total Citations (TC) to papers from different years with their usage counts in the WoS. U1 shows the numbers of usages in the last 180 days, and U2 gives the count since 2013. Our results of citation score indicator and usage counts U2 indicator demonstrate a similar trend in both with time since 2013 in all subject areas except mathematics. Usage counts (U2) are mostly higher than TC for recent years. This suggests that this altmetric indicator could attract attention to a publication at least a year before it could draw a significant number of citations. This indicator is now being used by many members of the Russian science community as an essential science indicator. U2 and TC do not contradict each other, but they do measure different behaviors.

Keywords: Science Citation Index-Expanded, Usage Counts, Citations, Subject Category, Open Access, Chemistry, Mathematics, Computer Science, Biochemistry, Neurosciences

DOI: https://doi.org/10.6025/stm/2020/2/14-22

\section{Introduction}

Traditional scientometrics, as originally defined (Nalimov \& Mulchenko, 1969) means "the quantitative methods of research on the development of science as an informational process". The speedy developments of modern communication and information technology significantly impacted the contemporary system of scientific communication. As a consequence, two new subfields of scientometrics were born: webometrics and altmetrics. J. Priem introduced the term "altmetrics" in 2010 https:// twitter.com/jasonpriem/status/25844968813. 
Altmetrics is "the study and use of scholarly impact measures based on activity in online tools and environments" (Priem J., et al, 2012). Also called Scientometrics 2.0, this field replaces journal citations with impacts in social networking tools such as views, downloads, "likes," blogs, Twitter, Mendeley, CiteULike (Mingles J.et al, 2015). We would like to indicate that a few studies performed by Phillips et al (1991) and Lewison et al (2008)) investigated the way the mass media, and in particular newspapers, publish stories about medical research.

Thelwall et al (2016) focused their research on medical publications (332,975 articles in 45 fields) indexed by Scopus in 2009. The study demonstrated a strong correlation between citations and Mendeley readership counts across all medical fields. According to the authors' opinions, altmetrics indicators should be used as a substitute for classical metrics. Since 2019 the Journal of Altmetrics Research, an Open Access journal, is operating due to the enthusiasm of outstanding scholar Prof. J. Bar-llan. A special issue of Scientometrics in 2020 was devoted to her intellectual contribution to scientometrics and altmetrics development (Haustein S, et al).

Heydari et al (2019) examined the relationship between altmetrics indicators and citations among 1,077 Highly Cited Articles (HCA) on surgery. Selected HCA were extracted from WoS and their altmetric score was selected from Altmetric Bookmarklet platform https://www.altmetric.com/about-our-data/our-sources. Authors found a positive but insignificant correlation (by Sperman) between the number of citations and the number of Mendeley readers. Remarkably, $37.4 \%$ of these HCA did not have an altmetric score. Authors opine that altmetrics could be used only as an additional indicator to citations. An extensive literature review on almetrics research was published by Fang et al (2020). The authors discuss the results of using altmetric indicators for identification of hot papers, which is a new trend in altmetrics research.

A significant growth of altmetrics research, based on Web of Science data (WoS), was observed during the previous three years (Kousha et al, 2020, Fang et al, 2020). The distinctiveness of classical citation metrics and altmetrics indicators was investigated in a comprehensive bibliometric analysis conducted by Chi et al (2019) on two subfields of chemistry: analytical chemistry (C1) and organic chemistry (C3). Three types of indicators (Capture, Citation, and Usage Counts) were selected and extracted from the following platforms: WoS, Scopus, Mendeley, EBSCO, CrossRef. The dataset of 39,736 papers in analytical chemistry and 27,531 papers in organic chemistry indexed by the WoS in 2013 were investigated. DOI identifications were used to match the dataset with PlumX. The results of the study showed significant correlations at different levels among various altmetric indicators. A high correlation was observed among classical citation indicators on the platforms that were studied.

In September 2015, the Web of Science (WoS, @ Clarivate Analytics) introduced two new indicators of research impact. They are designated as U1 and U2. U1 counts the numbers of "usages" of a paper in the last 180 days, and U2 counts the numbers since 2013. "Usage" means that the person who has searched for a paper in WoS has either attempted to download the full text, or has saved its record in a bibliographic reference manager (such as EndNote) or some other downloadable format. This is a new field of altmetrics, and it has led to several investigations that have attempted to compare these usage measures with citation counts (Markusova et al., 2018; Chi \&Glänzel, 2019; Lewison, 2020). The results have been somewhat inconclusive because they are measuring different behaviors. In principle, a researcher would first identify a paper of interest by way of its title, then read the abstract (normally easily available), perhaps obtain a full text, especially if it is Open Access, and then finally read the paper and cite it in a subsequent research paper of her own (Markusova et al, 2021).

The bibliometric performance of the Russian Academy of Sciences (RAS) and the Higher education sector (HES) played a very important role in the reform of basic research system (Markusova et al., 2016). In May 2012, President of the Russian Federation V. Putin released decree ${ }^{1} 599$, in which he set the following goal: "that the Russian share of research output (RO) has to reach $2.44 \%$ of the global RO, and five Russian universities have to be among the top hundred universities included in one of three world ranking systems in 2015" (Decree 599, 2012). A new project, denoted as Project 5-100 started in January 2014 when funding for 2013 was transferred to a selected group of universities. In June 2013, a new bill introduced and adapted quickly by Russian Parliament, related to the drastic reform of three government academies: the Russian Academy of Sciences (RAS), the Russian Academy of Agriculture and the Russian Academy of Medical Sciences. This reform caused controversy and strong resistance by the Russian research community. On November 1, 2013 D. Medvedev - the Prime Minister of the Russian Federation - released decree ${ }^{1} 979$ which ordered the inclusion in any research organization's evaluation, the following bibliometric indicators: number of papers, citation score and impact factor by Web of Science or Scopus. (see for instance http://www.ras.ru/news/shownews.aspx?id=613a30f8-1475-4d9a-a6a3-75df1501be7a) al, 2018) A few authors described the impact of government's research policy on bibliometric performance (Guskovet.al, 2016, Gilyarevskii et. al, 2019, Moed et.al, 2018, Markusova et. al, 2020).

There are further ambitious goals established in Decree N 204 published in December 2018 (http://static.kremlin.ru/media/ acts/files/0001201805070038.pdf). These would use research to propel the Russian into the top five economies of the world by 2024. The decree also established seven strategic priorities, and one of them Priority 1 (Item "A") was 
"Transition to advance digital, intelligent production technology, robotic systems, new material and methods of construction creation of systems for processing large volumes of data, machine learning and artificial intelligence". Seven subject categories (SC) on computer science by WoS were assigned to this priority.

The main goal of our empirical project was to examine the Russian research community attitudes and practice of using citation metrics (citation score -TC) and altmetric indicators in various disciplines.

\section{Methodology}

The main sources of bibliometric statistics were products produced by Clarivate Analytics: Science Citation Index -Expanded (SCl-E), Journal Citation Reports (JCR) and the analytical tool InCites. The search was restricted to SCI-E due to the history of the science structure in Russia, which is focused heavily on hard science. Search strategy was: "ADVANCED SEARCH: (CU=Russia and $P Y=2006-2019$ ). We downloaded the bibliographic metadata of 485,505 bibliographic records with an address in Russia in the years 2006-19. Metadata were collected in July 2020.

Two main indicators were selected for analysis: citation score and usage counts. Citation indicator is a valid indicator of research quality and widely used for research evaluation.

The usage indicator is a relatively novel indicator and shows only the interest or attention to a publication. Usage indicators have an advantage over a citation of appearing early, which speeds up knowledge distribution attracting attention to potentially "hot" paper.

To reveal similarity or the difference among various disciplines, we selected for evaluations the following subject categories (SC): Neurosciences, Biochemistry \& Molecular Biology (both belonging to life sciences), Chemistry Physical, Chemistry Inorganic\&Nuclear, Mathematics and the group of seven SC belonging to computer science that are part of research evaluation target set by V..V.Putin Decree. Russian outputs are given as integer counts, i.e., full credit is given for each paper that contains at least one Russian address.

The group named "Computer Sciences" consists of seven SC: Computer Science, Artificial Intelligence; Computer Science, Cybernetics; Computer Science, Hardware \& Architecture; Computer Science, Information Systems; Computer Science, Interdisciplinary Applications; Computer Science, Software Engineering; Computer Science, Theory \& Methods. We investigated an impact of open access (OA) journals on altimetric indicator U2 in 2013 that is the reference year of U2 indicator.

\section{Results and Discussion}

Since 2014 Russia's research output (RO) was growing annually (Moed et al, 2018). A similar positive trend is observed in the growth of Russian publications' citedness. For example, the share of Russian citations reached 54.5\% during $2015-2019$ compared to its share (48.5\%) in 2010-2014 (InCites, Clarivate Analytics). Russian ROtrendsare displayed at Figure 1.

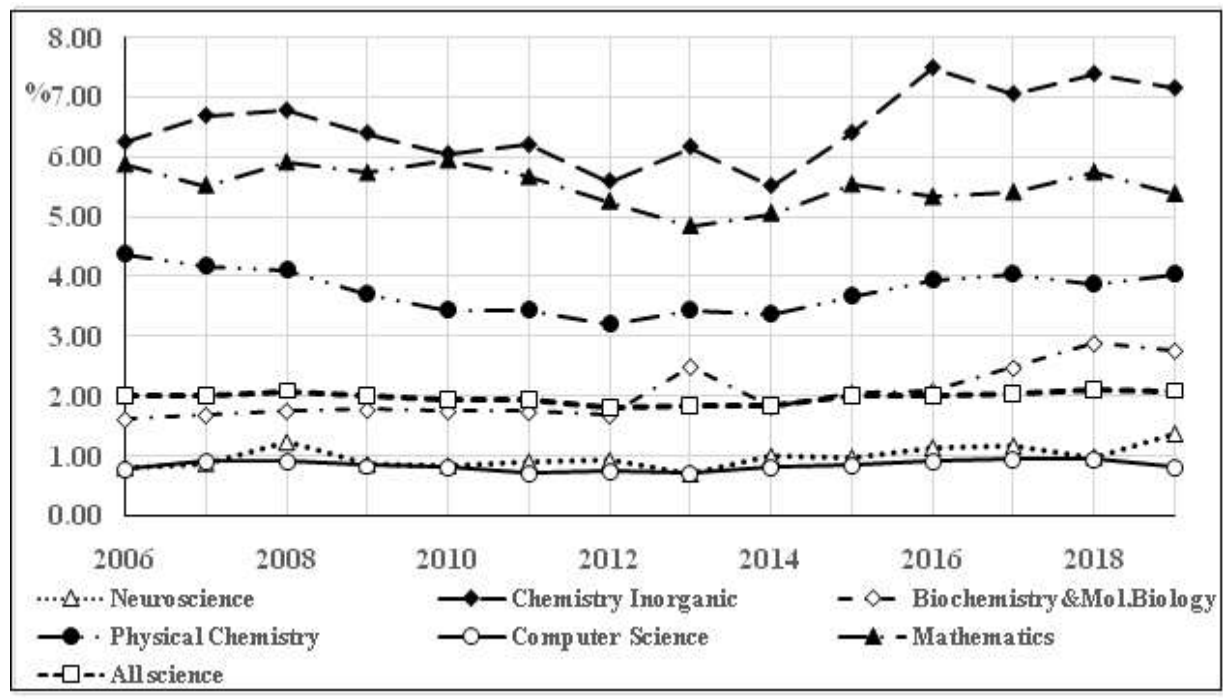

Figure 1. Russian research output and in six major fields (integer counts), SCI-E during 2006-2019 
Figure 1 displays the share of Russian publication (all types) indexed in SCI-E during 2006-2019, disaggregated by discipline in the world dataset. Our data show that the Russian publications share did not reach the target $2.44 \%$ set up by Russian government. As it was notified by Moed, et al (2018), the growth was observed due to significant increase of proceedings papers.

Among studied disciplines both SC on chemistry had significantly higher share compared with total RO share (2.1\%) in world dataset in 2019. The computer sciences share [which is the target of government research priority] is twice lower (less than $1 \%$ ) during all studied periods. Taking into account the growing role of computer sciences it's an alarming sign to Russian economy and prosperity. However, the growth in absolute numbers was observed as in Russian RO as in each studied discipline during 2006-2019. Two disciplines Biochemistry \& Molecular Biology and Neurosciences demonstrated the highest growth rate: 2.2 folds and 2.5 folds respectively.

Markusova et.al (2018) observed that Russian science is moving to Open Access which could possibly increase citations impact. Share of OA journals was $13.4 \%$ in 2013 and $28.3 \%$ in 2019 in total Russian RO in SCl-E. However, total share of OA Russian publication reached $40 \%$ in 2019 in three Indices of WoS (InCites). Razumova et.al, (2020) conducted a survey that revealed the growing changes in the attitude to Open Access in the Russian scholarly community compared to 2017 . Among 1,000 respondents from 884 organizations about $84 \%$ published articles in OA journals. Three quarters of respondents support mandatory OA publishing of research with state funding. The Russian Academy of Sciences (RAS) allowed free access to full-text journals published by RAS via https://elibrary.ru since July 2018 http://www.ras.ru/news/shownews.aspx?id=3afad7318d6d-47f6-b8bc-23bc3319e27c.

It is well-known that the citation indicator (TC) varies by discipline. The mean total citation scores (TC) for Russian publications in six subject categories presented in Table 1.

Table 1. Mean total citation (TC) scores for Russian publications in six subject areas in four years

\begin{tabular}{|l|l|l|l|l|l|l|c|}
\hline Year & Total RO & Biochem. & Neurosc. & Chem, Phys & Chem, I\&N & Compt. & Maths \\
\hline 2006 & 15.0 & 20.0 & 17.6 & 15.7 & 13.3 & 8.0 & 6.9 \\
2010 & 12.5 & 14.6 & 10.2 & 11.9 & 9.4 & 6.0 & 4.6 \\
2014 & 11.1 & 10.2 & 8.4 & 9.6 & 6.6 & 6.6 & 3.0 \\
2018 & 3.7 & 3.3 & 3.6 & 3.5 & 2.2 & 1.5 & 1.2 \\
\end{tabular}

It is very clear from Table 1 that the most cited papers of these six groups were those in the two subject areas of life sciences.

The graphs, Figures 2 to 7 , show the mean values of total citations (TC), and the two usage measures, U1 and U2. In all six graphs, mean U2 reaches a peak for papers published in 2013, because papers published earlier have "lost" some of their usage counts from their early years, when they normally attract the most interest. In the subsequent years, the curves of mean values of TC and U2 parallel each other. For most of them values of U2 exceed those of TC, indicating that scientists download more papers than they cite, as would be expected (Markusova etal., 2021).

Table 2. Mean usage count (U2) for Russian publications in six subject areas in four years

\begin{tabular}{|c|l|l|l|l|l|l|l|}
\hline Year & Total & Biochem & Neurosc. & Chem, Phys & Chem, I\&N & Comput. & Maths \\
\hline 2006 & 5.0 & 5.8 & 3.9 & 11.4 & 8.7 & 2.3 & 0.8 \\
2010 & 7.9 & 8.2 & 5.6 & 18.2 & 9.6 & 1.4 \\
2014 & 14.3 & 13.6 & 9.5 & 31.0 & 18.8 & 9.1 & 2.1 \\
2018 & 6.2 & 8.9 & 6.5 & 11.6 & 4.0 & 4.3 \\
\hline
\end{tabular}

During the last 10 years SC Biochemistry \&Molecular Biology was one of the strongest areas of research by number of 
publications in total Russian RO (Markusova et al, 2020). However, SC Neurosciences has a higher citation impact (TC score) 7.8 compared with 6.1 in SC Biochemistry \&Molecular Biology (InCites, 2010-2014). In our case, TC (20.0) indicator was the highest than in other SC in 2006. TC (10.2) indicator and U2 value (10.8) were close to each other in 2013. Share of OA journals was relatively high: $18.2 \%$ and $20.2 \%$ in publications on Neurosciences and Biochemistry \& Molecular Biology respectively. Users of both disciplines have a better access to OA journals than users of publication in any other discipline and in total RO (share 14.6\%) in 2013. The U1 indicator shows that the users of publications in Biochemistry \& Molecular Biology illustrate significant interest in literature published since 2017.

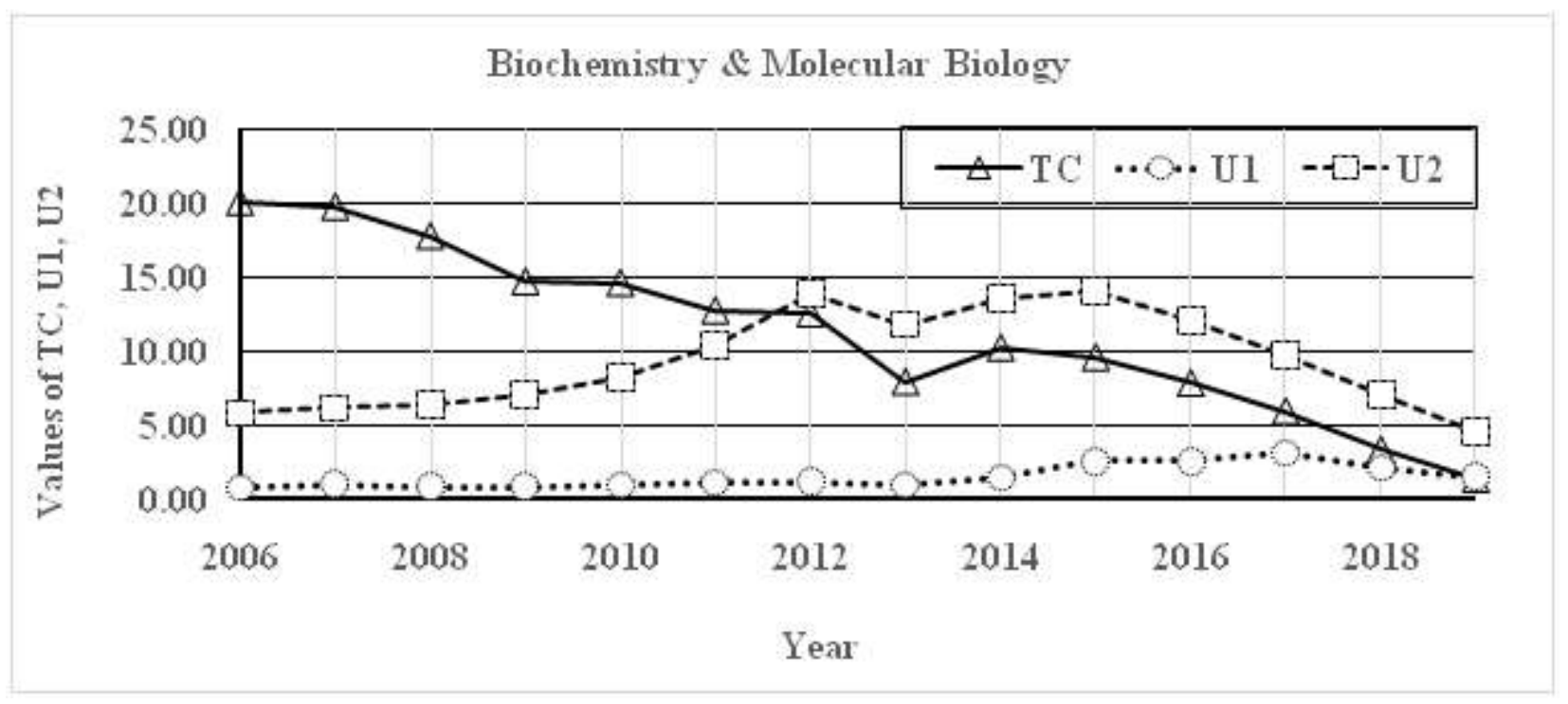

Figure 2. Mean values of total citations (TC) and usage counts U1 and U2 for Russian publications in Biochemistry \& Molecular Biology, SCI-E during 2006-2019

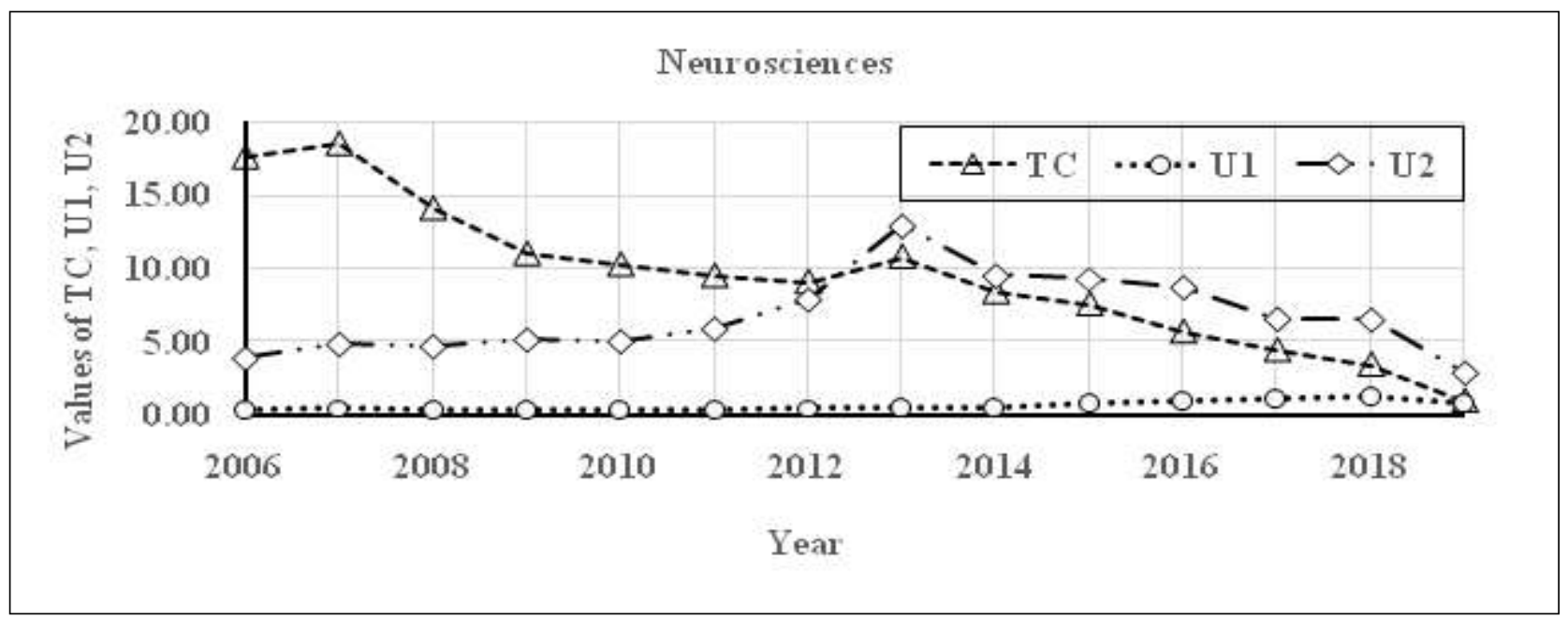

Figure 3. Mean values of total citations (TC) and usage counts U1 and U2 for Russian publications in Neurosciences, SCI-E

Russia as a country occupied 15th rank in SCI-E by number of RO. Among selected discipline Russian publications on Chemistry, Inorganic \& Nuclear captured the highest (fourth) rank in the world publications in 2013. As you can see from Fig. 3 , the value of TC in both Chemistry SC was close to each other in 2006 (13.3. and 15.6 respectively) and to the value of TC in total Russian RO. Chemistry papers receive a lot of usage in their first year, much more than those in mathematics (mean value below 0.3) and computer sciences (2.3). This confirms what is known about this subject, that papers take a long time to emerge (some require many months to be checked by reviewers), and take even longer to have an impact. Strikingly high are values of usage indicators U2 for SC Chemistry Physical and SC Chemistry Inorganic \& Nuclear: 33.4 and 21.2 corre- 
spondingly in 2013. If we juxtapose curves TC and U2, we observe that TC curve and value of usage counts U2 are equidistant since 2013. We would like to notify that in 2006 U2 for both SC on Chemistry were significantly higher (in two or three folds) than in other four. We assume that this artifact is related to availability of OA journals. Shares of OA journals were very low: $3.6 \%$ in Chemistry, Physical and $5.1 \%$ in Chemistry, Inorganic \& Nuclear, far below the corresponding values for total Russian RO (14.6\%) (Markusova at el). And a check on 12 papers with the highest U2 counts showed that they were closed access, with the full text only available through the journal publisher. Despite a strong movement of the science community to Open Science, the share of OA journals on chemistry was between 5.2\% (Chemistry, Physical) and $8.1 \%$ (Chemistry, Inorganic \& Nuclear) in the world dataset in 2013.

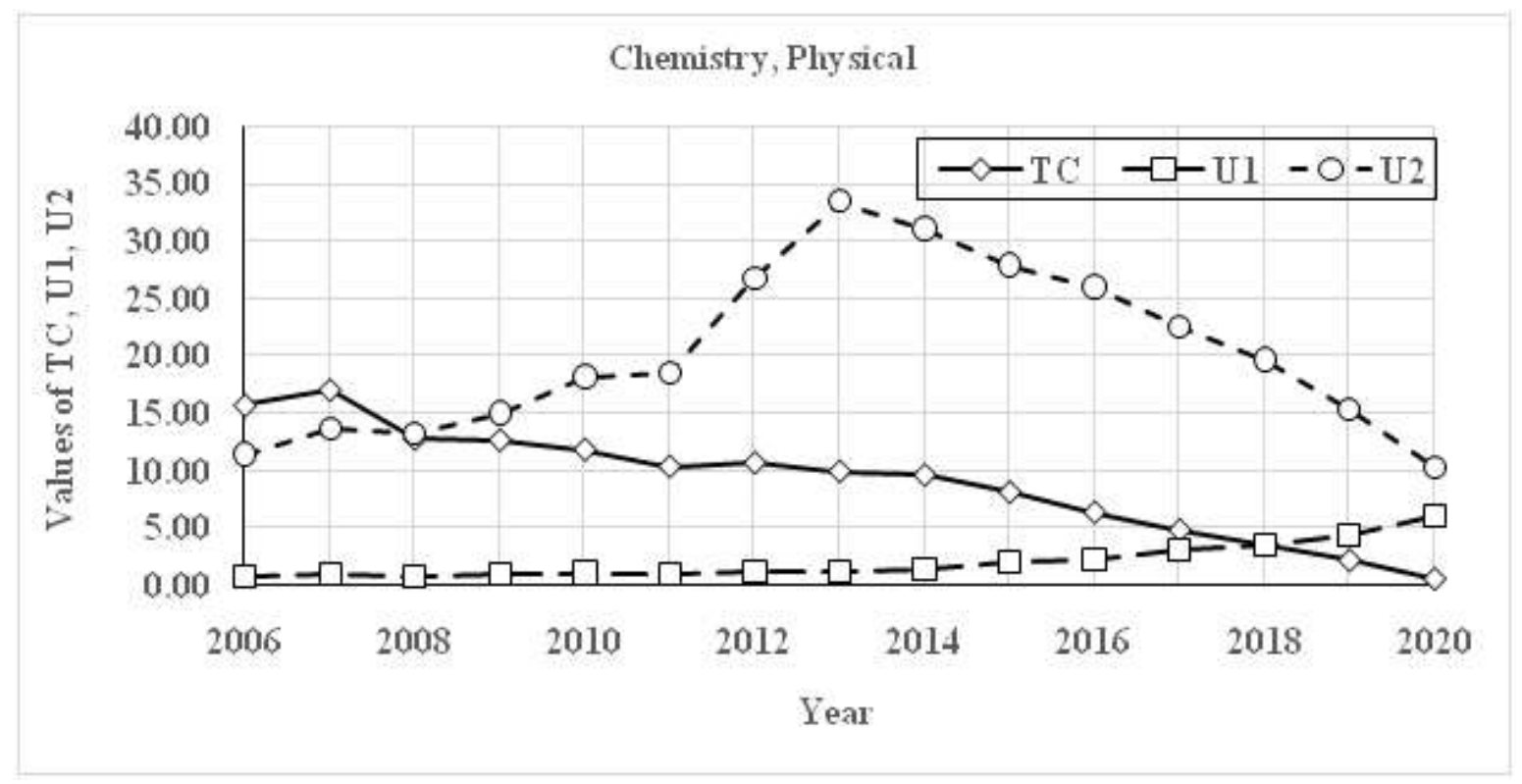

Figure 4. Mean values of total citations (TC) and usage counts U1 and U2 for Russian publications in Chemistry Physical, SCI-E

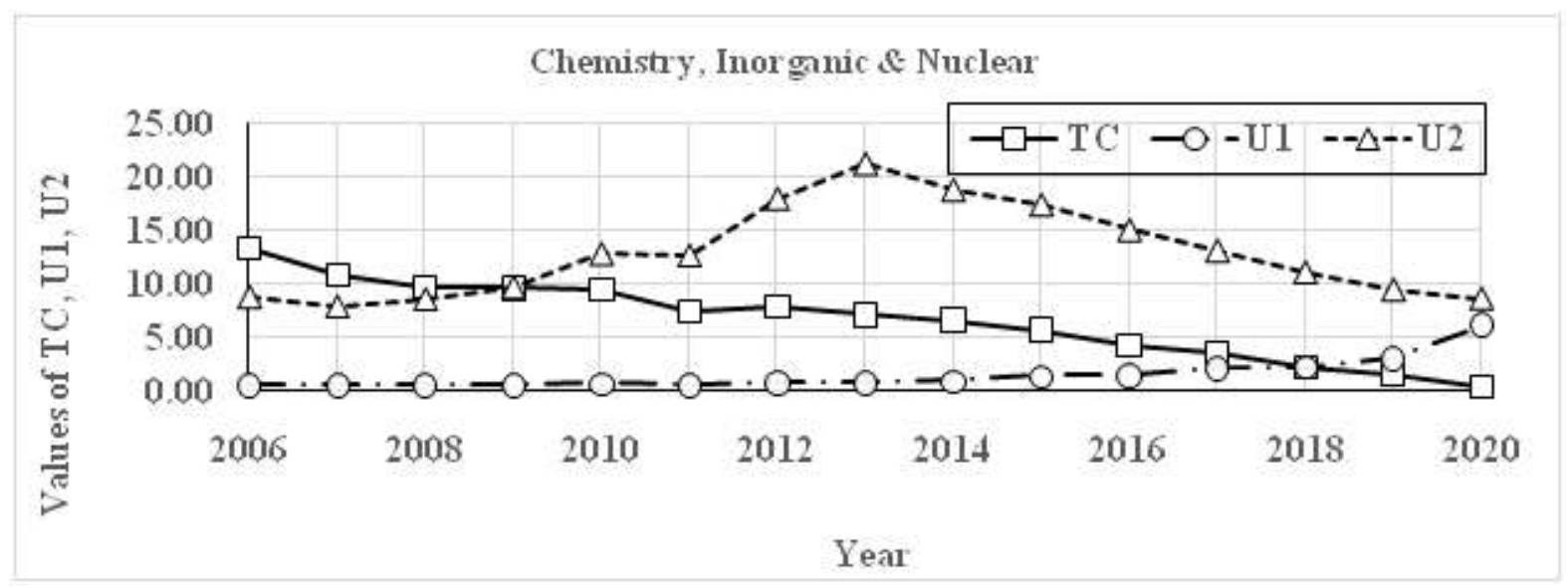

Figure 5. Mean values of total citations (TC) and usage counts U1 and U2 for Russian publications in Chemistry, Inorganic \& Nuclear papers, SCI-E

Russian science demonstrated a robust tendency toward "hard sciences" during the studied period (Markusova and et al., 2020). Mathematics is the strongest area of basic research in Russia. Its share is 5.5\% in total Russian RP for 2015-2019, which is twice higher than in the world dataset (InCites). That is why an attention to usage indicator U2 is interesting object of study.

However, its average TC score is much lower than that of the other five disciplines, see Table 1 . The same is even more so with respect to U2, which value was small and stable, around 2.0 since 2012 until 2018. Partly, it could be influenced by the 
availability of full text publication. Really, the share of OA journals was the highest $(23.1 \%)$ compared to the share of OA with any studied research area in 2013.

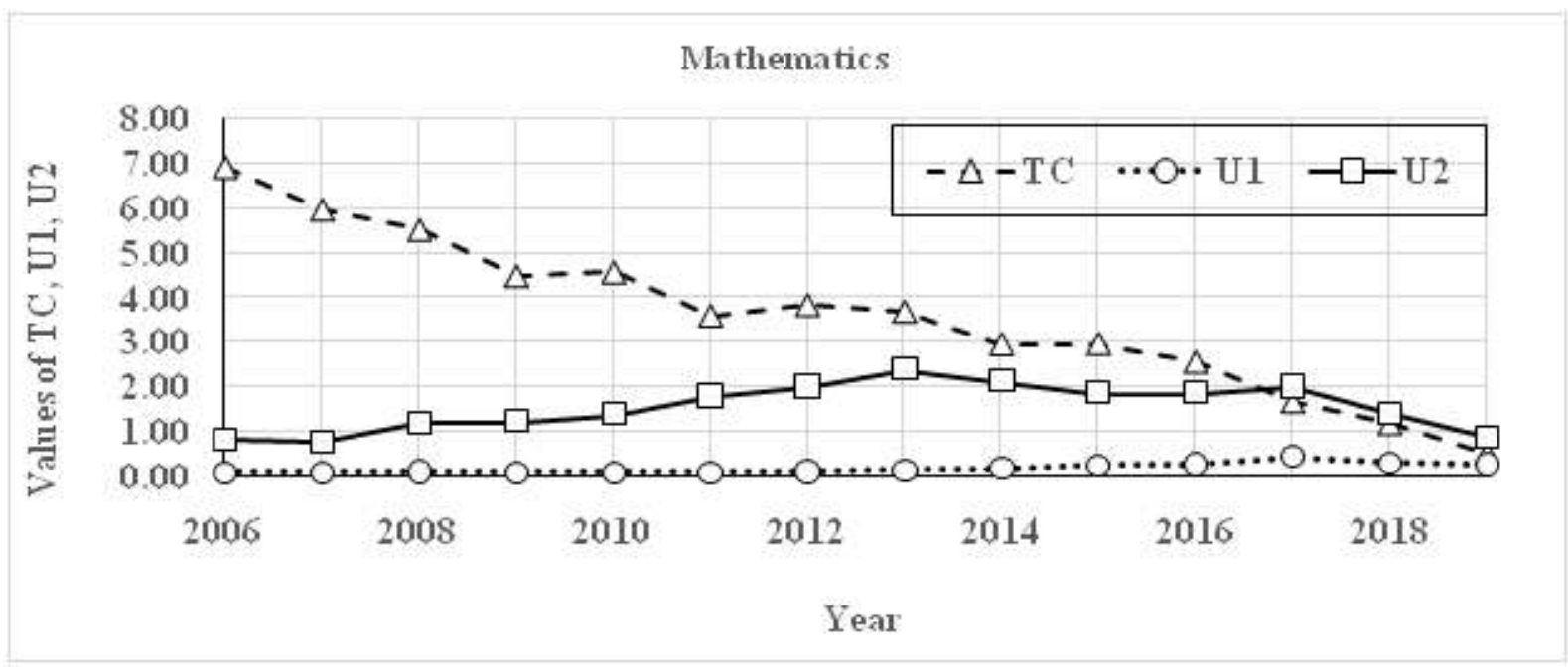

Figure 6. Mean values of total citations (TC) and usage counts U1 and U2 for Russian publications in Mathematics, SCI-E

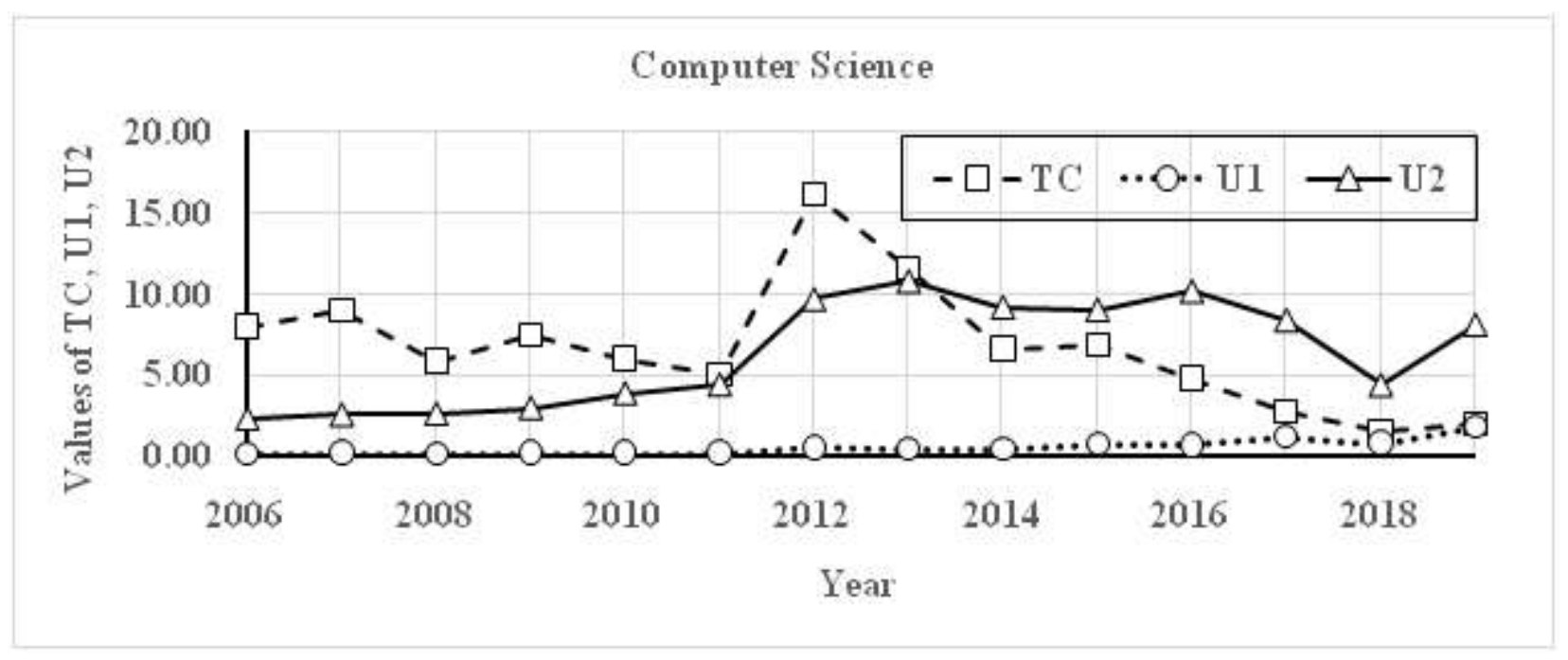

Figure 7. Mean values of total citations (TC) and usage counts U1 and U2 for Russian publications in Computer Sciences, SCI-E

As mentioned above, one of the strategic priorities selected by the Russian government is speedy development of computer sciences. Seven SC were assigned to this group named Computer Sciences. The growth of those publications was 1.8 folds which is quite similar to the growth in 1.9 folds in the world dataset during 2006-2019. This is why Russian share was stable (less than 1\%) during 2006-2019. TC score (8.7) was a little bit higher than in Mathematics (see Table 1). However, U2 value was approximately five times higher than U2 value in Mathematics from 2013 until 2019. It was not surprising because the users in Computer Sciences had approximately twice less access to full-text OA journals than for the users in Mathematics: shares of OA were $11.2 \%$; and $23.1 \%$ respectively in 2013 .

\section{Conclusions}

Our results of citation score indicator and usage counts U2 indicator since 2013 demonstrate a similar trend in both with time in all subject areas except mathematics.

Publications on SC Chemistry Physical, and SC Chemistry, Inorganic \& Nuclear have the highest frequency of usage count 
U2 compared with other disciplines: 33.37 and 21.22 respectively in 2013 . Partly it is attributed to very low access to full-text availability: the share of OA journals was very low (5.1) \% compared to other studied disciplines.

After 2013, the mean value of U2 is substantially higher than TC. This suggests that this altmetric indicator could attract attention to a publication at least a year before it could attract a significant number of citations. We could state that users of the Russian science community valued downloaded count U2 as an essential source of SCI-E information. Cultural, sociological and historical tradition have influenced altmetric indicators and citation's behavior in any research community.

Results show that classical bibliometric indicators (citation) and altimetric indicators (U2) do not contradict each other, but they do measure different behaviors.

\section{Acknowledgments}

We express our gratitude to Dr. G. Lewison for valuable advice. Authors are grateful to the Russian Foundation for Basic Research (grants 20-07-00014) for financial support, and to Clarivate Analytics for the opportunity to use their data.

\section{References}

[1] Begum, M., Lewison, G., Jassem, J., et al. (2018). Mapping cancer research across Central and Eastern Europe, the Russian Federation and Central Asia: implications for future national cancer control planning. European Journal of Cancer, 104, 127-136 https://doi.org/10.1016/j. ejca. 2018.08.024 PMID: 30347288

[2] Chi, PS., Gorraiz, J., Glänzel, W. (2019). Comparing capture, usage and citation indicators: an altmetric analysis of journal papers in chemistry disciplines. Scientometrics, 20(3), 1461-1473

[3] Gilyarevskii, R., Libkind, A., Markusova, V. (2019). Dynamics of Russian publications activity 1993-2017. Automatic Documentation and Mathematical Linguistics, 53(2), 51-63.

[4] Guskov, A., Kosyakov, D., Selivanova, I. (2016). Scientometric research in Russia: impact of science policy changes. Scientometrics, 107, 287-303. (2016)

[5] Fang, Z., Costas, R., Tian, W., Wang, X., Wouters, P. (2020). An extensive analysis of the presence of altmetric data for Web of Science publications across subject fields and research topics. Scientometrics, https://doi.org/10.1007/s11192-02003564-9

[6] Haustein, S., Peters, I. (2020). Commemorating Judit Bar-llan from bibliometric and altmetric perspectives. (2020). Scientometrics, 123, 1211-1224 https://doi.org/10.1007/s11192-020-03448-y

[7] Heydari, S., Shekofteh, M., Kazerani, M. (2019) Relationship between Altmetrics and Citations: A Study on the Highly Cited Research Papers. DESIDOC, Journal of Library \& Information Technology, 39 (4), 169-174. URL: https://doi.org/10.14429/ djlit.39.4.14204

[8] Kousha, Thelwall, M. (2020). COVID-19 publications: Database coverage, citations, readers, tweets, news, Facebook walls, Reddit posts 2021 Quantitative Science Studies, 1(3) https://www.mitpressjournals.org/doi/full/10.1162/qss_a_00066

[9] Lewison, G., Tootell, S., Roe, P., Sullivan, R. (2008). How do the media report cancer research? A study of the UK's BBC website. British Journal of Cancer, 99, 569 - 576. doi:10.1038/sj.bjc.6604531

[10] Lewison, G. (2020). Web of Science usage information: a preliminary exploration of U1 and U2. Second International Conference on Science and Technology Metrics. Chinese Academy of Sciences, Zhuhai, China, 7-9 December 2020. http:// socio.org.uk/stm/

[11] Markusova, V. A., Bogorov, V. G., Libkind, A. N. (2018). Usage Metrics vs Classical Metrics: Analysis of Russia's Research Output. Scientometrics, 114(2), 593-603. URL: https://doi.org/10.1007/s11192-017-2597-2

[12] Markusova, V., Mindeli, L., Libkind, A., Zolotova, A., Akoev, M. (2020). Comparative Analysis of Russian and industrialized countries performance on Energy and Fuels, WoS, 2008-2017.Scientometrics, 123 (3), 1281-1300. DOI: https://doi.org/10.1007/ s11192-020-03440-6

[13] Markusova, V., Lewison, G., Zolotova, A., Libkind, I., Libkind, A. (2021). A comparison of citation scores and Web of Science usage counts for Russian science papers, 2006-19. Submitted to ISSI-2021.

[14] Mingels, J., Leydesdorff, L. (2015). A Review of Theory and Practice in Scientometrics. European Journal of Operational Research. DOI: 10.1016/j.ejor.2015.04.002, http://authors.elsevier.com/sd/article/S037722171500274X

[15] Moed, H., Markusova, V., Akoev, M. (2018). Trends in Russian research output indexed in Scopus and Web of Science. 
Scientometrics, 118 (2), 1153-1180. URL: https://doi.org/10.1007/s11192-018-2769-8.

[16] Nalimov, V., Mulchenko, Z. (1969). Naukometriya. IzuchenieRazvitiyaNaukikakInformatsionnogoProtsessa. [Scientometrics. Study of the Development of Science as an Information Process], Nauka, Moscow, (English translation: 1971. Washington, D.C.: Foreign Technology Division. U.S. Air Force Systems Command, Wright-Patterson AFB, Ohio. (NTIS Report No.AD735634).

[17] Passport nacional'nogoproekta «Nauka». UtverzhdenprezidiumomSovetapriPrezidenteRossijskojFederacii po strategicheskomurazviti- yuinacional'ny'mproektam (protokolot 24 dekabrya $2018 \mathrm{~g}$. N16) / Oficial'ny'jsajtPravitel'stvaRossii. (In Russian). http://static.government.ru/media/files/vCAoi8zEXRVSuy2Yk7D8hv QbpbUSwO8y.pdf

[18] Phillips, DP., Kanter, EJ., Bednarczyk, B., Tastad, PK. (1991). Importance of the lay press in the transmission of medical knowledge to the scientific community. New England Journal ofMedicine, 325: 1180-1183

[19] Priem, J., Taraborelli, D., Groth, P., Neylon, C. (2010). Altmetrics: A manifesto. http://altmetrics.org/manifesto/

[20] Priem, J., Groth, P., Taraborelli, D. (2012). The Altmetrics Collection. PLoS ONE, 7(11), e48753. https://doi. org/10.1371/ journal.pone.0048753.

[21] Razumova, I. K., Litvinova, N. N., Shvartsman, M. E., Kuznetsova, Yu. (2018). Attitude to Open Access in Russian scholarly community: 2018. Survey results and analysis. Scholarly Research and Information. 2018; 1(1): 6-21. (In Russ.) https:// doi.org/10.24108/2658-3143-2018-1-1-6-21

[22] Thelwall, M., Wilson, P. (2016). Mendeley Readership Altmetrics for Medical Articles: An Analysis of 45 Fields. Journal of the Association for Information Science and Technology, 67(8), 1962-1972. DOI: 10.1002/asi.23501.

[23] Widener, A. (2018). European research funders demand open access. Chemical \& Engineering News, 96(36), 14. 